\title{
Dengue research in India: A scientometric analysis of publications, 2003-12
}

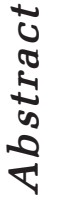

\section{Ritu Gupta, Rishi Tiwari', Mueen Ammed $\mathrm{KK}^{2}$}

Sector 4, Panchkula 134113, ${ }^{1}$ Birla Institute of Management \& Technology, Noida,

${ }^{2}$ Director, SciBiolMed.Org, No. 24, Bore Bank Cross Road, Harris Main Road, Benson Town, Bangalore, India

Address for the correspondence: Dr. Mueen Ammed KK, Director, SciBiolMed.Org, No. 24, Bore Bank Cross Road, Harris Main Road, Benson Town, Bangalore, India

E-mail: mueen.ahmed@gmail.com

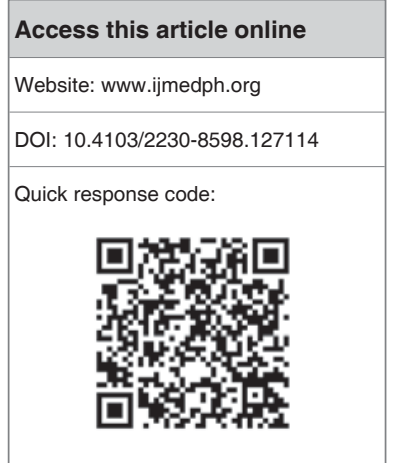

The present study quantitatively analyze Indian dengue research output during the 10 years from 2003 to 2012, using Scopus international multidisciplinary database. The study focused on global publication output, share, rank, and citation impact of top 15 most productive nations, India's publications output, growth, global publication share and research impact, international collaborative papers share in national output and the share of major international collaborative partner countries in total India's international collaborative papers, contribution of various sub-fields and distribution by population age groups, productivity and citation impact of its leading Indian institutions and authors and Indian contribution in most productive journals. Indian contribution in dengue fever research consisted of 910 papers, which increased from 27 papers in 2003 to 193 papers in 2012, witnessing an annual average growth rate of $28.19 \%$. Among the top 15 most productive countries, India holds second position in dengue fever research output, with global publication share of $10.22 \%$ during $2003-12$. The average citation per paper scored by India was 3.27, the least among the top 15 most productive countries during 2003-12. India's share of international collaborative papers was $10.55 \%$ during $2003-12$, which increased from $9.12 \%$ during $2003-07$ to $11.13 \%$ during $2008-12$. The present India's research efforts in dengue research are low in view of the 50,222 cases of dengue in 2012 alone. The country needs to increase its research output and also increase its research impact substantially particularly through enhanced national and international collaboration, besides evolving a national policy for identification, monitoring and control of dengue cases and also evolving a research strategy with sufficient funding commitment to solve this growing national problem.

Key words: Dengue, India, scientometric

\section{INTRODUCTION}

Viruses are tiny agents that can infect a variety of living organisms, including bacteria, plants, and animals. Like other viruses, the dengue virus is a microscopic structure that can only replicate inside a host organism. The dengue viruses are members of the genus Flavivirus in the family Flaviviridae. Along with the dengue virus, this genus also includes a number of other viruses transmitted by mosquitoes and ticks that are responsible for human diseases. Flavivirus includes the yellow fever, West Nile, Japanese encephalitis, and tick-borne encephalitis viruses. ${ }^{[1]}$

Dengue fever (DF), also known as breakbone fever, is an infectious tropical disease, caused by the dengue virus. Symptoms include fever, headache, muscle and joint pains, and a characteristic skin rash (similar to measles). In smaller proportion of cases, the disease develops into the life threatening dengue hemorrhagic fever (DHF) resulting in bleeding low levels of blood platelets and blood plasma leakage, or into dengue shock syndrome (DSS), where dangerously low blood pressure occurs. ${ }^{[2]}$

DF is caused by any of the four closely related viruses, namely DEN-1, DEN-2, DEN-3, and DEN-4. These four viruses are called serotypes because each has different interactions with the antibodies in human blood serum. The four dengue viruses are similar — they share approximately $65 \%$ of their genomes - but even within a single serotype, there is some genetic variation. Despite these variations, infection with each of the dengue serotypes results in the same disease and range of clinical symptoms. ${ }^{[1]}$ 
Dengue is transmitted between people by the mosquitoes Aedes aegypti and Aedes albopictus, which are found throughout the world. The Aedes aegypti mosquitoes are the primary vector of dengue. The virus is transmitted to humans through the bites of infected female mosquitoes. The Aedes aegypti mosquitoes live in urban habitats and breeds mostly in manmade containers. Unlike other mosquitoes Aedes aegypti is a day time feeder, its peak biting periods are early in the morning and in the evening before dusk. Aedes albopictus, a secondary dengue vector in Asia, has spread largely due to international trade in used tyres (a breeding habitat) and other goods (e.g., lucky bamboo). ${ }^{[3]}$

The incidence of dengue has grown dramatically around the world in recent decade. Over 2.5 billion people - over $40 \%$ of the world's population - are now at risk from dengue. The incidence of dengue has increased 30 -fold over the past 50 years. World Health Organization (WHO) currently estimates that they may be 50-100 million dengue infections worldwide every year. Before 1970, only nine countries have experienced severe dengue epidemics. The disease is now endemic in more than 100 countries. As estimated, 500,000 people with severe dengue are hospitalized each year, a large proportion of them are children. About $2.5 \%$ of those affected die. ${ }^{[3]}$

Several southeast Asian countries are seeing record numbers of people infected with DF, a mosquito-borne virus for which there is currently no approved vaccine or specific drug treatment. Researchers from the University of Oxford and the Wellcome Trust estimated that $70 \%$ of the world's serious dengue cases are in Asia, with India alone accounting for $34 \%$ of the total. ${ }^{[4]}$

The Directorate of National Vector Borne Disease Control Program (NVBDCP) is the central nodal agency for the prevention and control of vector borne diseases, that is, malaria, dengue, lymphatic filariasis, kala-azar, Japanese encephalitis, and chikungunya in India. It is one of the Technical Departments of Directorate General of Health Services, Government of India. There has been a surge in dengue cases in the country in 2012 when as many as 50,222 cases were reported against 18,860 in 2011 . According to India's Health Minister, 28,292 cases were reported during the year 2010. He said in view of upsurge and geographical spread of dengue to newer areas, a mid-term plan has been developed by Government of India for prevention and control of dengue and many advisories have been issued from time to time to control and manage the outbreak of dengue in India. Field visits are carried out to assess the preparedness and to provide technical guidance to states. Training is also imparted to clinicians on case management as per Government of India guidelines and to other health care functionaries on program activities. For augmenting diagnostic facilities, the number of Sentinel Surveillance Hospitals (SSHs) with laboratory support has been increased to 347 across the country from 110 and linked with 14 apex referral laboratories with advanced diagnostic facilities for back up support for dengue across the country. ${ }^{[5]}$

The Department of Biotechnology (DBT) of India has launched a program to promote and accelerate research activities in containing dengue disease and enhance the capacity and capability of those committed to dengue research. Establishment of dengue laboratory network program with defined gene amplifications for understanding the genotypes, serotypes, strengthening regional laboratories for rapid and confirmatory diagnosis of suspected dengue cases, development of integrated companion diagnostic tests $(\mathrm{Ag} / \mathrm{Ab})$ and new rapid point of care diagnostic test systems and validation, and novel strategies for vaccine development has be promoted under the initiative. It will also enable utilization of primary human cell targets to understand the translational data on platelet, monocytes, DCs, and endothelial cells by using stem cell technology, studies on pathogenic antibodies in dengue hemorrhagic fever (their generation, specificity, regulation, seroepidemiology, etc.), development of advanced research program on platelet pathology and study on molecular markers of neurotropism and vector preference. ${ }^{[6]}$

\section{Literature review}

Few studies have been undertaken in the past on scientometric analysis of dengue research output. Dutt et al..$^{[7]}$ analysed 2566 papers on global research output in dengue, as covered in Science Citation Index (SCI)-Expanded from 1987 to 2008. The total output came from 74 countries of which 17 countries contributed $87 \%$ of the total output. The highest number of publications came from USA, followed by India. More than half of the scientific output is concentrated among four sub-disciplines of microbiology and virology, immunology and vaccine, epidemiology, and entomology. Among the prolific institutions, the publication output of institutions from the US and Taiwan had higher impact. About $80 \%$ of the papers appeared in journals originating from USA, the UK, the Netherlands, France, and Germany. Raja et al. ${ }^{[8]}$ also analyzed world DF publication from 1999 to 2012, as covered in SCI database. The publications data is analyzed to know the authorship pattern, degree of collaboration and geographical distribution of papers, year-wise research output, geographical distribution of research output, and nature of collaboration, characteristics of highly productive institution and the channel of communication used by the scientists.

No paper has been published focusing on the analyses of Indian dengue research output till today. However, Gupta et al. analyzed bibliometric characteristics of Indian publications on several other diseases, such as typhoid, ${ }^{[0]}$ diabetes,${ }^{[10]}$ tuberculosis, ${ }^{[11]}$ malaria, ${ }^{[12]}$ asthma, ${ }^{[13]} \mathrm{HIV} / \mathrm{AIDS},{ }^{[14]}$ and measles. ${ }^{[15]}$

\section{Objectives of the study}

The main objectives of this study are to analyze the research performance of India in DF research during 2003-12, based on publications output, as indexed in Scopus database. In particular, the study focuses on the following objectives:

1. To study the global research output and the contribution of top 15 countries in terms of global share and rank and research quality;

2. To study Indian research output, its growth, rank, global publication share and citation impact; 
3. To study the share of international collaboration in Indian publication output and the contribution of different collaborating countries;

4. To study the Indian contribution by sub-fields and by type of population groups;

5. To study the publication productivity and the impact of Indian leading institutions and authors; and

6. To study the media of communication

\section{Materials and Methods}

The study retrieved the publications data on India and top 15 most productive countries in dengue research from the Scopus database (http://www.scopus.com) for 10 years from 2003 to 2012. The keyword "dengue" was used in "title, abstract and keyword field" along with India in "country field" and "2003 to 2012" in time field was used for searching the main publication data used in the study and this become the main search string. Similar strings were used to generate to generate publications output data on top 15 countries. For generating citation impact data, the 3, 2, 1, and zero years' citation window was used for publications during 2003-09, 2010, 2011, and 2012. For searching the international collaborative papers, a separate search strategy, which combines India's collaboration with more than 200 countries, was prepared and this string was combined with main search strategy string to generate India's total international collaborative papers and contribution of leading countries in India's collaborative papers. For analyzing institutional, author, and journals output, separate search strategies were developed, which later combined with the main search string to generate the desired output.

\section{Analysis}

The global publication share to top 15 most productive countries in dengue research varies from $2.38 \%$ to $25.26 \%$ during $2003-12$. The USA tops the list with global publication share of $25.26 \%$, followed far behind by India (10.22\% share and second rank), Brazil (9.75\% share and third rank), Thailand, UK, France, and Singapore (their global publication share ranging from $4.32 \%$ to $7.39 \%$ and rank from fourth to seventh), Australia, Taiwan, and Malaysia (their global publication share ranging from $3.02 \%$ to $3.81 \%$ and rank from eight to tenth) and Japan, China, Cuba, Germany and Mexico (their global publication share ranging from $2.38 \%$ to $2.77 \%$ and rank from $12^{\text {th }}$ to $15^{\text {th }}$ ) during 2003-12 [Table 1].

Among the top 15 most productive countries, (i) the publication share of developing countries has increased: India (from 8.86\% to $10.94 \%$ ), Brazil (from $8.57 \%$ to $10.38 \%$ ), Singapore (from $3.56 \%$ to $4.73 \%$ ), Malaysia (from $2.30 \%$ to $3.41 \%$ ), China (from $2.00 \%$ to $2.74 \%$ ), and Mexico (from $2.20 \%$ to $2.48 \%$ ) in contrast to decrease in case of Thailand (from $8.50 \%$ to $6.80 \%$ ), Taiwan (from $3.62 \%$ to $3.15 \%$ ), and Cuba (from $2.78 \%$ to $2.70 \%$ ) from 2003-07 to $2008-12$ and (ii) the publication share of developed countries has decreased in USA (from $25.70 \%$ to $25.02 \%$ ), Japan (from $2.85 \%$ to $2.74 \%$ ), and Germany (from $3.01 \%$ to $2.48 \%$ ) as against increase in UK (from $6.11 \%$ to $6.45 \%$ ), France (from $5.79 \%$ to $6.56 \%$ ), and Australia (from $3.75 \%$ to $3.84 \%$ ) from $2003-07$ to $2008-12$.

Among the top 15 most productive countries, the publication rank has increased in France (from $6^{\text {th }}$ to $5^{\text {th }}$ ), Singapore (from $9^{\text {th }}$ to $7^{\text {th }}$ ), Malaysia (from $13^{\text {th }}$ to $9^{\text {th }}$ ), and China (from $15^{\text {th }}$ to $11^{\text {th }}$ ) as against decrease in UK (from $5^{\text {th }}$ to $6^{\text {th }}$ ), Australia (from $7^{\text {th }}$ to $8^{\text {th }}$ ), Taiwan (from $8^{\text {th }}$ to $10^{\text {th }}$ ), Japan (from $11^{\text {th }}$ to $12^{\text {th }}$ ), Cuba (from $12^{\text {th }}$ to $13^{\text {th }}$ ), Germany (from $10^{\text {th }}$ to $14^{\text {th }}$ ), and Mexico (from $14^{\text {th }}$ to $15^{\text {th }}$ ) from 2003-07 to 2008-12. During the same period, the publication rank has remained the same in USA, India, Brazil, and Thailand [Table 1].

In terms of research impact, the ranks have altered compared to ranks in publication productivity. The highest rank in terms of research impact among 15 most productive countries is occupied by UK with average citation per paper of 11.76 (with $5^{\text {th }}$ rank in

\begin{tabular}{|c|c|c|c|c|c|c|c|c|c|c|c|}
\hline \multirow{2}{*}{$\begin{array}{l}\text { Name of } \\
\text { country }\end{array}$} & \multicolumn{3}{|c|}{ Number of papers } & \multicolumn{3}{|c|}{ Share of papers } & \multicolumn{3}{|c|}{ Rank of papers } & \multirow[t]{2}{*}{ TC } & \multirow[t]{2}{*}{ ACPP } \\
\hline & 2003-07 & 2008-12 & 2003-12 & 2003-07 & 2008-12 & 2003-12 & 2003-07 & 2008-12 & 2003-12 & & \\
\hline USA & 795 & 1454 & 2249 & 25.70 & 25.02 & 25.26 & 1 & 1 & 1 & 26020 & 11.57 \\
\hline India & 274 & 636 & 910 & 8.86 & 10.94 & 10.22 & 2 & 2 & 2 & 2978 & 3.27 \\
\hline Brazil & 265 & 603 & 868 & 8.57 & 10.38 & 9.75 & 3 & 3 & 3 & 4412 & 5.08 \\
\hline Thailand & 263 & 395 & 658 & 8.50 & 6.80 & 7.39 & 4 & 4 & 4 & 4707 & 7.15 \\
\hline UK & 189 & 375 & 564 & 6.11 & 6.45 & 6.33 & 5 & 6 & 5 & 6634 & 11.76 \\
\hline France & 179 & 381 & 560 & 5.79 & 6.56 & 6.29 & 6 & 5 & 6 & 5208 & 9.30 \\
\hline Singapore & 110 & 275 & 385 & 3.56 & 4.73 & 4.32 & 9 & 7 & 7 & 2895 & 7.52 \\
\hline Australia & 116 & 223 & 339 & 3.75 & 3.84 & 3.81 & 7 & 8 & 8 & 3061 & 9.03 \\
\hline Taiwan & 112 & 183 & 295 & 3.62 & 3.15 & 3.31 & 8 & 10 & 9 & 2720 & 9.22 \\
\hline Malaysia & 71 & 198 & 269 & 2.30 & 3.41 & 3.02 & 13 & 9 & 10 & 1110 & 4.13 \\
\hline Japan & 88 & 159 & 247 & 2.85 & 2.74 & 2.77 & 11 & 12 & 11 & 1427 & 5.78 \\
\hline China & 62 & 182 & 244 & 2.00 & 3.13 & 2.74 & 15 & 11 & 12 & 1240 & 5.08 \\
\hline Cuba & 86 & 157 & 243 & 2.78 & 2.70 & 2.73 & 12 & 13 & 13 & 1346 & 5.54 \\
\hline Germany & 93 & 144 & 237 & 3.01 & 2.48 & 2.66 & 10 & 14 & 14 & 1997 & 8.43 \\
\hline Mexico & 68 & 144 & 212 & 2.20 & 2.48 & 2.38 & 14 & 15 & 15 & 1257 & 5.93 \\
\hline World & 3093 & 5812 & 8905 & 100.00 & 100.00 & 100.00 & & & & 66948 & 7.52 \\
\hline
\end{tabular}


publication productivity), followed by USA (11.57) with $1^{\text {st }}$ rank in publication productivity, France $(9.30)$ with $6^{\text {th }}$ rank in publication productivity, Taiwan $(9.22)$ with $9^{\text {th }}$ rank in publication productivity, Australia (9.03) with $8^{\text {th }}$ rank in publication productivity, Singapore (7.52) with $7^{\text {th }}$ rank in publication productivity, Germany (8.43) with $14^{\text {th }}$ rank in publication productivity, etc. The developed countries have performed better in terms of research impact than most developing countries.

India ranks is at second position among the top 15 most productive countries in DF research with its global publication share of $10.22 \%$ during 2003-12. Its global publication share has increased from $8.86 \%$ to $10.94 \%$ from $2003-07$ to $2008-12$. However, in terms of research impact, the average citation per paper scored by India was 3.27 , the least among the top 15 most productive countries during 2003-12 [Table 1].

\section{India's contribution, citation impact, and international collaboration}

Indian contribution in DF research has increased from 27 papers in 2003 to 193 papers in 2012, witnessing an annual average growth rate of $28.19 \%$. The average citation impact per paper registered by India's research in DF during 2003-12 was 3.27, which has decreased from 4.37 during 2003-07 to 2.79 during 2008-12. India has contributed $10.55 \%$ international collaborative papers share in DF research during 2003-12, which has increased from $9.12 \%$ during 2003-07 to $11.13 \%$ during 2008-12 [Table 2].

Fifteen countries have published five or more collaborative papers with Indian scientists in dengue research during 2003-12. The largest contribution to international collaborative papers of India in dengue research comes from USA (with $42.71 \%$ share), followed by UK (20.83\% share), Australia (11.46\% share), Sri Lanka (11.46\% share), Canada (10.42\% share), Thailand (10.42\% share), Malaysia ( $9.38 \%$ share), Brazil (8.33\% share), etc. It is observed that India's international collaboration has increased with Thailand by $14.08 \%$, Malaysia by $12.68 \%$, UK by $11.94 \%$, Indonesia by $7.04 \%$, Germany by $3.04 \%$, and Vietnam $(1.63 \%)$ in contrast to decrease in USA by $12.56 \%$, Sri Lanka by $11.55 \%$, France by $9.18 \%$, Canada by $7.55 \%$, Brazil by $4.96 \%$, Philippines by $2.37 \%$, Singapore by $0.96 \%$, Switzerland by $0.73 \%$, and Australia by $0.73 \%$ from $2003-07$ to 2008-12 [Table 3].

\section{Subject-Wise distribution of dengue research output}

India's publication output in dengue research during 2003-12 has been published in the context of seven sub-fields (as reflected in database classification based on journal title subject), with highest publication

\begin{tabular}{|c|c|c|c|c|c|}
\hline Period & TP & $\mathrm{TC}$ & ACPP & ICP & \%ICP \\
\hline 2003 & 27 & 80 & 2.96 & 4 & 14.81 \\
\hline 2004 & 41 & 159 & 3.88 & 3 & 7.32 \\
\hline 2005 & 64 & 309 & 4.83 & 7 & 10.94 \\
\hline 2006 & 80 & 457 & 5.71 & 6 & 7.50 \\
\hline 2007 & 62 & 192 & 3.10 & 5 & 8.06 \\
\hline 2008 & 98 & 567 & 5.79 & 11 & 11.22 \\
\hline 2009 & 79 & 398 & 5.04 & 14 & 17.72 \\
\hline 2010 & 114 & 432 & 3.79 & 13 & 11.40 \\
\hline 2011 & 152 & 281 & 1.85 & 14 & 9.21 \\
\hline 2012 & 193 & 103 & 0.53 & 19 & 9.84 \\
\hline 2003-07 & 274 & 1197 & 4.37 & 25 & 9.12 \\
\hline 2008-12 & 636 & 1781 & 2.79 & 71 & 11.13 \\
\hline 2003-12 & 910 & 2978 & 3.27 & 96 & 10.55 \\
\hline
\end{tabular}

\begin{tabular}{|c|c|c|c|c|c|c|}
\hline \multirow[t]{2}{*}{ Collaborating country } & \multicolumn{3}{|c|}{ Number of papers } & \multicolumn{3}{|c|}{ Share of papers } \\
\hline & 2003-07 & 2008-12 & 2003-12 & 2003-07 & 2008-12 & 2003-12 \\
\hline USA & 13 & 28 & 41 & 52.00 & 39.44 & 42.71 \\
\hline UK & 3 & 17 & 20 & 12.00 & 23.94 & 20.83 \\
\hline Australia & 3 & 8 & 11 & 12.00 & 11.27 & 11.46 \\
\hline Sri Lanka & 5 & 6 & 11 & 20.00 & 8.45 & 11.46 \\
\hline Switzerland & 3 & 8 & 11 & 12.00 & 11.27 & 11.46 \\
\hline Canada & 4 & 6 & 10 & 16.00 & 8.45 & 10.42 \\
\hline Thailand & 0 & 10 & 10 & 0.00 & 14.08 & 10.42 \\
\hline Malaysia & 0 & 9 & 9 & 0.00 & 12.68 & 9.38 \\
\hline Brazil & 3 & 5 & 8 & 12.00 & 7.04 & 8.33 \\
\hline Singapore & 2 & 5 & 7 & 8.00 & 7.04 & 7.29 \\
\hline Germany & 1 & 5 & 6 & 4.00 & 7.04 & 6.25 \\
\hline Philippines & 2 & 4 & 6 & 8.00 & 5.63 & 6.25 \\
\hline Indonesia & 0 & 5 & 5 & 0.00 & 7.04 & 5.21 \\
\hline France & 3 & 2 & 5 & 12.00 & 2.82 & 5.21 \\
\hline Vietnam & 1 & 4 & 5 & 4.00 & 5.63 & 5.21 \\
\hline Total international collaborating & 25 & 71 & 96 & & & \\
\hline
\end{tabular}

\section{papers of India}

In all international collaborative papers of India, there may be one or more collaborating countries. As a result, the combined output of 15 foreign collaborating countries listed above in Indian international collaborative output will be more than its total international collaborative papers 
output coming from medicine (686 papers, $75.38 \%$ share), followed by immunology and microbiology (266 papers, 29.23\% share), biochemistry, genetics and molecular biology (149 papers, 16.37\% share), agricultural and biological sciences (45 papers, 4.95\% share), pharmacology, toxicology, and pharmaceutics (38 papers, $4.18 \%$ share), neurosciences (33 papers, 3.63\% share), and environment science (26 papers, $2.86 \%$ share) during 2003-12 [Table 4].

On analyzing the citation impact of dengue research under different sub-fields, it was found that neurosciences had scored the highest citation impact (4.70 citations per paper), followed by immunology and microbiology (4.62 citations per paper), biochemistry, genetics and molecular biology (4.01 citations per paper), agricultural and biological sciences (3.40 citations per paper), pharmacology, toxicology, and pharmaceutics (3.27 citations per paper), medicine (3.02 citations per paper), and environment science (1.27 citations per paper) during 2003-12 [Table 4].

\section{Dengue research output by population age group}

On classifying the dengue research output by population age group during 2003-12, it was observed that the largest share $(28.35 \%)$ comes from adults, followed by child (21.43\% share), adolescents (19.78\% share), middle-aged (10.99\% share), and aged (6.59\% share). Of these population group, the publication share has increased in case of adults (from $25.55 \%$ to $29.56 \%$ ), adolescents (from $18.61 \%$ to $20.28 \%$ ), middle-aged (from $9.12 \%$ to $11.79 \%$ ), and aged (from $6.20 \%$ to $6.76 \%$ ), as against decrease in child (from $25.55 \%$ to $19.6 \%$ ) from 2003-07 to 2008-12 [Table 5].

\section{Profile of 15 productive Indian institutions in dengue research}

The top 15 most productive Indian institutions involved in dengue research have published 14 or more papers each during 2003-12.
These 15 institutions involved in dengue research together have contributed $41.87 \%$ (381 papers) in the cumulative publications output of India in dengue research. The publication profile of these 15 institutions along with their research output, citations received and h-index values are presented in Table 6 . The average publication productivity per institution reported by the top 15 institutions was 25.4 and only 7 institutions have registered higher output than the group average. These are All India Institute of

\begin{tabular}{|c|c|c|c|c|}
\hline Sub-fields* & TP & TC & ACPP & \%TP \\
\hline Medicine & 686 & 2069 & 3.02 & 75.38 \\
\hline Immunology and microbiology & 266 & 1228 & 4.62 & 29.23 \\
\hline $\begin{array}{l}\text { Biochemistry, genetics, and } \\
\text { molecular biology }\end{array}$ & 149 & 598 & 4.01 & 16.37 \\
\hline Agricultural and biological sciences & 45 & 153 & 3.40 & 4.95 \\
\hline $\begin{array}{l}\text { Pharmacology, toxicology, and } \\
\text { pharmaceutics }\end{array}$ & 38 & 128 & 3.37 & 4.18 \\
\hline Neurosciences & 33 & 155 & 4.70 & 3.63 \\
\hline Environment science & 26 & 33 & 1.27 & 2.86 \\
\hline Total of the country & 910 & & & \\
\hline
\end{tabular}

TP $=$ Total papers, $\mathrm{TC}=$ Total citations, ACPP $=$ Average citation per paper, $*$ There is some overlapping of papers under sub-fields. As a result, the combined output of India under seven sub-fields will be more than its actual total output

\begin{tabular}{|c|c|c|c|c|c|c|}
\hline \multirow{2}{*}{$\begin{array}{l}\text { Population } \\
\text { group }\end{array}$} & \multicolumn{3}{|c|}{ Number of papers } & \multicolumn{3}{|c|}{ Share of papers } \\
\hline & 2003-07 & 2008-12 & $2003-12$ & $2003-07$ & 2008-12 & 2003-12 \\
\hline Adults & 70 & 188 & 258 & 25.55 & 29.56 & 28.35 \\
\hline Child & 70 & 125 & 195 & 25.55 & 19.65 & 21.43 \\
\hline Adolescent & 51 & 129 & 180 & 18.61 & 20.28 & 19.78 \\
\hline Middle aged & 25 & 75 & 100 & 9.12 & 11.79 & 10.99 \\
\hline Aged & 17 & 43 & 60 & 6.20 & 6.76 & 6.59 \\
\hline Total & 274 & 636 & 910 & 100.00 & 100.00 & 100.00 \\
\hline
\end{tabular}

\begin{tabular}{|c|c|c|c|c|}
\hline Name of the Institution & TP & TC & ACPP & H-Index \\
\hline All India Institute of Medical Sciences, New Delhi & 40 & 183 & 4.58 & 8 \\
\hline National Institute of Virology, Pune & 39 & 222 & 5.69 & 10 \\
\hline Sant Paramanand Hospital, Delhi & 38 & 20 & 0.53 & 2 \\
\hline C S Medical University, Lucknow & 36 & 114 & 3.17 & 7 \\
\hline Defence Research \& Development Establishment, Gwalior & 32 & 170 & 5.31 & 11 \\
\hline Sanjay Gandhi Postgraduate Institute of Medical Research, Lucknow & 27 & 108 & 4.00 & 7 \\
\hline National Institute of Communicable Diseases, Delhi & 25 & 55 & 2.20 & 7 \\
\hline Postgraduate Institute of Medical Education \& Research, Chandigarh & 23 & 35 & 1.52 & 5 \\
\hline Maulana Azad Medical College, Delhi & 23 & 68 & 2.96 & 6 \\
\hline Vector Control Research Centre, Pondicherry & 20 & 55 & 2.75 & 5 \\
\hline International Centre for Genetics \& Biotechnology, Delhi & 18 & 174 & 9.67 & 10 \\
\hline Bharathiar University, Coimbatore & 17 & 74 & 4.35 & 4 \\
\hline National Institute of Malaria Research, Delhi & 15 & 32 & 2.13 & 3 \\
\hline Christian Medical College, Vellore & 14 & 58 & 4.14 & 8 \\
\hline Christian Medical College, Ludhiana & 14 & 38 & 2.71 & 5 \\
\hline Total & 381 & 1406 & 3.69 & 6.53 \\
\hline Indian total output & 910 & & & \\
\hline Share of Top 15 institutions in Indian total output & 41.87 & & & \\
\hline
\end{tabular}


Medical Sciences, New Delhi with 39 papers, followed by National Institute of Virology, Pune (39 papers), Sant Parmanand Hospital, Delhi (38 papers), C S Medical University, Lucknow (36 papers), Defence Research \& Development Establishment, Gwalior (32 papers), and Sanjay Gandhi Postgraduate Institute of Medical Sciences, Lucknow (27 papers). The average citation per paper registered by the total papers of these 15 institutions was 3.69 during 2003-12 and 7 institutions have registered higher citation impact than the group average. They are International Centre for Genetics \& Biotechnology, New Delhi with citation impact per paper of 9.67, followed by National Institute of Virology, Pune (5.69), Defence Research \& Development Establishment, Gwalior (5.31), All India Institute of Medical Sciences, New Delhi (4.58), Bharathiar University, Coimbatore (4.35), Sanjay Gandhi Postgraduate Institute of Medical Sciences, Lucknow (4.0), and Christian Medical College, Vellore (4.14). The average h-index value of these 15 Indian institutions was 6.53 and 7 Indian institutions have achieved higher h-index value than the group's average. These are Defence Research \& Development Establishment, Gwalior with h-index value of 11, followed by National Institute of Virology, Pune (10), International Centre for Genetics \& Biotechnology, New Delhi (10), All India Institute of Medical Sciences, New Delhi (8), C S Medical University (8), Sanjay Gandhi Postgraduate Institute of Medical Sciences, Lucknow (7), and National Institute of Communicable Diseases, Delhi (7).

\section{Profile of top 15 most productive authors in dengue research}

The top 15 most productive Indian authors involved in dengue research have published 12 or more papers each during 2003-12.
The publication profile of these 15 authors along with their research output, citations received, and h-index values are presented in Table 7. These 15 authors involved in dengue research together have contributed $32.75 \%$ (298 papers) in the cumulative publications output of India in dengue research during 2003-12. Seven institutions have registered higher publications share than the group average of 19.87. They are A. Arya with research output of 39 papers, followed by N. Agarwal (36 papers), S. Swaminathan (24 papers), N. Khanna (23 papers), U. C. Chaturvedi (20 papers), B. K. Tyagi (20 papers) and M. Parida (20 papers). Seven authors have registered (5.33) more than the average citation per paper of the 15 Indian institutions. They are A. M. Jana with average citation per paper of 9.92, followed by N. Khanna (9.70), S. Swaminathan (9.33), P. K. Dash (8.47), U. C. Chaturvedi (8.35), M. Parida (8.20) and P. V. L. Rao (6.65) during 2003-12. Eight authors have registered more than the average h-index (6.87) of the 15 Indian institutions during 2003-12. They are N. Khanna and S. Swaminthan with h-index of 11 each, followed by M. Parida (10), P.K. Dash, and P. V. L. Rao (9 each), U. C. Chaturvedi and A. M. Jana (8 each) and A. Chakravarthy (7) [Table 7].

\section{Research communication in high productive journals}

The 15 most productive journals publishing Indian research papers in dengue research together contributed 306 papers, which accounts for $33.63 \%$ share of the total output of India during 2003-12. The cumulative publications output share of these 15 most productive journals showed a decrease in India's publications output from $42.70 \%$ during $2003-07$ to $29.87 \%$ during $2008-12$ [Table 8].

\begin{tabular}{|c|c|c|c|c|c|}
\hline Name of the author & Address of the author & TP & TC & ACPP & H-Index \\
\hline S. Arya & Sant Paramnand Hospital, Delhi & 39 & 20 & 0.51 & 2 \\
\hline N. Agarwal & Sant Paramnand Hospital, Delhi & 36 & 18 & 0.50 & 2 \\
\hline S. Swaminathan & International Centre for Genetics \& Biotechnology, Delhi & 24 & 224 & 9.33 & 11 \\
\hline N. Khanna & International Centre for Genetics \& Biotechnology, Delhi & 23 & 223 & 9.70 & 11 \\
\hline U. C. Chaturvedi & K.G.Medical University, Lucknow & 20 & 167 & 8.35 & 8 \\
\hline B. K. Tyagi & Centre for Research in Medical Entomology, Madurai & 20 & 82 & 4.10 & 6 \\
\hline M. Parida & Defence Research \& Development Establishment, Gwalior & 20 & 164 & 8.20 & 10 \\
\hline P. V. L. Rao & Defence Research \& Development Establishment, Gwalior & 17 & 113 & 6.65 & 9 \\
\hline A. Chakravarti & Maulana Azad Medical College, Delhi & 16 & 56 & 3.50 & 7 \\
\hline P. K. Dash & Defence Research \& Development Establishment, Gwalior & 17 & 144 & 8.47 & 9 \\
\hline K. Murugan & Bharathiar University, Coimbatore & 15 & 73 & 4.87 & 4 \\
\hline U. K. Misra & $\begin{array}{l}\text { Sanjay Gandhi Postgraduate Institute of Medical Research, } \\
\text { Lucknow }\end{array}$ & 13 & 65 & 5.00 & 5 \\
\hline V. Thenmozhi & Centre for Research in Medical Entomology, Madurai & 13 & 55 & 4.23 & 6 \\
\hline J. Kalita & $\begin{array}{l}\text { Sanjay Gandhi Postgraduate Institute of Medical Research, } \\
\text { Lucknow }\end{array}$ & 13 & 65 & 5.00 & 5 \\
\hline A. M. Jana & Defence Research \& Development Establishment, Gwalior & 12 & 119 & 9.92 & 8 \\
\hline Total & & 298 & 1588 & 5.33 & 6.87 \\
\hline Total Indian papers & & 910 & & & \\
\hline \multirow{2}{*}{$\begin{array}{l}\text { Share of } 15 \text { authors in } \\
\text { Indian output }\end{array}$} & & 32.75 & & & \\
\hline & & 19.87 & & & \\
\hline
\end{tabular}




\begin{tabular}{|c|c|c|c|}
\hline \multirow[t]{2}{*}{ Name of journal } & \multicolumn{3}{|c|}{ Number of papers } \\
\hline & 2003-07 & 2008-12 & 2003-12 \\
\hline Dengue Bulletin & 40 & 13 & 53 \\
\hline Indian Journal of Medical Research & 20 & 25 & 45 \\
\hline Parasitology Research & 0 & 29 & 29 \\
\hline Journal of Communicable Diseases & 8 & 19 & 27 \\
\hline Indian Journal of Pediatrics & 7 & 17 & 24 \\
\hline $\begin{array}{l}\text { Indian Journal of Medical } \\
\text { Microbiology }\end{array}$ & 5 & 13 & 18 \\
\hline Journal of Vector Borne Diseases & 3 & 14 & 17 \\
\hline Indian Pediatrics & 6 & 7 & 13 \\
\hline $\begin{array}{l}\text { Journal of the Indian Medical } \\
\text { Association }\end{array}$ & 1 & 11 & 12 \\
\hline Virology Journal & 4 & 8 & 12 \\
\hline $\begin{array}{l}\text { Asian Pacific Journal of Tropical } \\
\text { Medicine }\end{array}$ & 1 & 12 & 12 \\
\hline $\begin{array}{l}\text { Journal of the Association of } \\
\text { Physicians of India }\end{array}$ & 8 & 3 & 11 \\
\hline Neurology India & 2 & 9 & 11 \\
\hline $\begin{array}{l}\text { American Journal of Tropical } \\
\text { Medicine \& Hygiene }\end{array}$ & 4 & 7 & 11 \\
\hline Indian Journal of Practical Pediatrics & 8 & 3 & 11 \\
\hline Total & 117 & 190 & 306 \\
\hline Total Indian papers & 274 & 636 & 910 \\
\hline Share of 15 journals in Indian output & 42.70 & 29.87 & 33.63 \\
\hline
\end{tabular}

\section{SUMMARY AND CONCLUSIONS}

Indian contribution in DF research consisted of 910 papers, which increased from 27 papers in 2003 to 193 papers in 2012, witnessing an annual average growth rate of $28.19 \%$. Among the top 15 most productive countries, India holds second position in DF research output, with global publication share of $10.22 \%$ during 2003-12. India's global publication share has increased from $8.86 \%$ to $10.94 \%$ from $2003-07$ to $2008-12$. The average citation impact per paper on a 3-year citation window registered by India's research output in DF research was 3.27 during 2003-12, which has decreased from 4.37 to 2.79 from 2003-07 to 2008-12. The international collaborative share of India in dengue research output was $10.55 \%$ during $2003-12$, which had increased from $9.12 \%$ to $11.13 \%$ from $2003-07$ to $2008-12$. Among top 15 foreign countries publishing international collaborative papers with India in dengue research, the largest contribution comes from USA with $42.71 \%$ share, followed by UK (20.83\% share), Australia (11.46\% share), Sri Lanka (11.46\% share), Canada (10.42\% share), Thailand (10.42\% share), Malaysia ( $9.38 \%$ share), Brazil (8.33\% share), etc. In terms of sub-field-wise break-up of Indian dengue research publications during 2003-12, the largest share of publication $(75.38 \%)$ comes from medicine, followed by immunology and microbiology (29.23\% share), biochemistry, genetics and molecular biology (16.37\% share), agricultural and biological sciences (4.95\% share), pharmacology, toxicology, and pharmaceutics ( $4.18 \%$ share), neurosciences (3.63\% share), and environment science $(2.86 \%$ share). Among different population age groups, the largest focus of research on dengue was on adults (with $28.35 \%$ share), followed by child (21.43\% share), adolescents (19.78\% share), middle-aged (10.99\% share) and aged (6.59\% share) during 2003-12. Among the Indian institutions contributing to dengue research, only 15 have published 14 or more papers each during 2003-12 and together have contributed $41.87 \%$ publication share to the cumulative publications output of India in dengue research. The average citation per paper and h-index registered by the total papers of these 15 institutions was 3.69 and 6.53, respectively, during 2003-12. Among the Indian authors contributing to dengue research, only 15 have published 14 or more papers each during 2003-12 and together have contributed $32.75 \%$ share to the cumulative publications output of India in dengue research. The average citation per paper and h-index registered by the total papers of these 15 authors was 5.33 and 6.87, respectively, during 2003-12. Among various journals publishing Indian dengue research papers, the top 15 journals have contributed $33.63 \%$ share of the total output of India during 2003-12, which has decreased from $42.70 \%$ to $29.87 \%$ from $2003-07$ to $2008-12$.

The severity of the dengue endemic in India is underestimated by lack of accurate information related to the incidence and cost of dengue illness. Furthermore, the manifestation of dengue in India appears to be changing from its benign form to its severe forms of DHF and DSS. This change is leading to an increase in the frequency of outbreaks, morbidity, and mortality. Dengue is a notifiable disease in India since 1996. However, misdiagnosis and underreporting of dengue cases persist due to clinical definition challenges, scarcity of diagnostic tools, and lack of healthcare providers' familiarity with dengue

The huge hike in dengue cases is posing questions about the way India is going about its dengue prevention and control strategy aimed at source reduction. The government is now trying to rope in rural and urban local bodies for carrying out a special campaign for sanitation and cleanliness, fogging, increasing sentinel surveillance sites and training of health personnel.

Dengue mortality can be reduced by implementing early case detection and appropriate management of severe cases; reorienting health services to identify early cases and manage dengue outbreaks effectively; and training health personnel, along with appropriate referral systems, at primary health-care levels. Dengue morbidity can be reduced by implementing improved outbreak prediction and detection through coordinated epidemiological and entomological surveillance; promoting the principles of integrated vector management and deploying locally adapted vector control measures including effective urban and household water management. Effective communication can achieve behavioral outcomes that augment prevention programs. Research will continue to play an important role in reversing the trend in dengue, a 
neglected tropical disease, by improving methods and systems for surveillance, prevention, and control.

India urgently needs a permanent dengue surveillance system to monitor and control a mosquito-borne viral disease. Existing technologies such as geographical information systems, polymerase chain reaction, rapid antigen tests, genetic sequencing, and bioinformatics can be harnessed to provide a holistic approach to suppress dengue resurgence, in collaboration with the WHO's Dengue Net. Databases could be continuously updated and the reporting of dengue cases from India's existing network of institutions and laboratories standardized, with a view to predicting epidemics and reducing fatality rates.

India's research output is very low keeping in view of 50,222 cases of dengue in India in 2012 alone. Therefore, the country needs to increase its research output and also increase its research impact substantially particularly through enhanced national and international collaboration. There is also need to evolve a national policy of identification, monitoring, and control of dengue cases and also evolving a research strategy with sufficient funding commitment and involvement of different type of Indian organizations to solve this growing national problem.

\section{REFERENCES}

1. Dengue viruses concept. Scitable by Nature Education, 2013. Available from: http://www.nature.com/scitable/topicpage/dengueviruses-22400925 [Last accessed on 2013 Sep 11].

2. Dengue fever, 8 September 2012. Available from: http://www.en.wikipedia. org/wiki/Denguefever [Last accessed on 2013 Sep 11].

3. Dengue and severe dengue, Fact sheet $N^{\circ} 117$. September 2013. Available from: http://www.who.int/mediacentre/factsheets/fs117/en/ [Last accessed on 2013 Sep 11].
4. University of Washington. Asia Pacific Emerging Infection Network Dengue. July 8, 2013. Available from: http://blogs.uw.edu/apecein/tag/ dengue/\#.UjAXadKBkrY [Last accessed on 2013 Sep 11].

5. Surge in dengue cases in India in last couple of years. Buisness Standard September 12, 2013. Available from: http://www.business-standard. com/article/pti-stories/surge-in-dengue-cases-in-india-in-last-couple-ofyears-1130806011481 [Last accessed on 2013 Sep 12].

6. Joseph A. DBT launches programme to enhance capacity, capability in dengue research, 24 May 2013. Available from: http://pharmabiz.com/ NewsDetails. aspx?aid=75509\&sid=1 [Last accessed on 2013 Sep 12].

7. Dutt B, Kumar S, Garg KC. Scientometric profile of global dengue research. Collnet J Scientometr Inf Manag 2010;4:81-91.

8. Raja S, Kumar RP, Amsaveni N. Citation analysis of dengue fever 19992012: A global perspective. Int J Basic Appl Med Sci 2012;2.

9. Gupta BM, Bala A, Baidwan K, Chaddha N, Singh HS. Mapping of typhoid research in India: A scientometric analysis of publications output in 20002009. Chin Librariansh 2010;31. Available from: http://www.icle.us/cliej/ Bc131GBBCC.pdf

10. Gupta BM, Kaur H, Bala A. Mapping of Indian diabetes research during 1999-2008. DESIDOC J Libr Inf Technol 2011;31:71-80.

11. Gupta BM, Bala A. Mapping of tuberculosis research in India: A scientometric analysis of publications output during 1998-2009. Collnet J Scientometr Inf Manag 2011;5:1-19.

12. Gupta BM, Bala A. A bibliometric analysis of malaria research in India during 1998-2009. J Vector Borne Dis 2011;48:163-70.

13. Gupta BM, Bala A. Mapping of asthma research in India. A scientometric analysis of publications output during 1999-2008. Lung India 2011;28:239-46.

14. Gupta BM, Bala A, Kaur H. Mapping of HIVIAIDS research in India: A scientometric analysis of publications output during 1999-2008. Collnet J Scientometrs Inf Manag 2011;5:185-203.

15. Bala A, Gupta BM. Measles: A quantitative analysis of world publications during 20001-10. J Scientometr Res 2012;1:60-70.

How to cite this article: Gupta R, Tiwari R, Ammed KM. Dengue research in India: A scientometric analysis of publications, 2003-12. Int J Med Public Health 2014;4:1-8.

Source of Support: Nil. Conflict of Interest: No conflict of Interest. 